\title{
Relationship Between Oxygen Radical Absorbance Capacity (ORAC) Index, Body Composition and Blood Biochemical Markers in Overweight /Obese Compared to Normal Weight Subjects: A Cross- Sectional Study
}

\section{Zahra Madani}

Islamic Azad University Science and Research Branch

Maryam Moussavi Javardi

Islamic Azad University Science and Research Branch

Ghazaleh Khalili

Islamic Azad University Science and Research Branch

\section{Sayed Abolghassem Djazayeri}

Tehran University of Medical Sciences

Ariyo Movahedi ( $\square$ amm35@mail.aub.edu )

Islamic Azad University Science and Research Branch

Majid Karandish

Ahvaz Jundishapur University: Ahvaz Jondishapour University of Medical Sciences

\section{Research}

Keywords: Oxygen Radical Absorption Capacity (ORAC), Lipid Profile, Fasting blood Glucose, Obesity, Overweight.

Posted Date: November 30th, 2020

DOI: https://doi.org/10.21203/rs.3.rs-109641/v1

License: (c) (i) This work is licensed under a Creative Commons Attribution 4.0 International License.

Read Full License 


\section{Abstract}

Background: Obesity is an important preventable disease, which promotes the development of chronic disorders by altering several factors including oxidative stress. Dietary antioxidants protect the body against oxidative stress. The purpose of this study was to evaluate the potential association of oxygen radical absorbance capacity (ORAC) index with obesity and its associated features in adults.

Methods: participants were divided in two groups of normal weight and overweight /obesity. General characteristics were registered and a 147-item food frequency questionnaire was completed. Thereafter, anthropometric measurements were conducted. Biochemical indices were obtained from science and Research branch of Islamic Azad University of Tehran, Iran. The amount of the dietary ORAC index was estimated using the data provided by the USDA Foods Table.

Results: The results showed that there was a significant difference between the normal and overweight/obese groups in terms of body mass index (BMI) and waist-to-hip ratio (WHR) ( $P=0.0001)$. Participants with normal weight consumed more fruits and vegetables than another group. Also, the dietary ORAC index in normal individuals was higher than the case group, but there was not significant difference $(P=0.352)$. There was also a significant inverse correlation between dietary ORAC and $B M I$ and WHR, whereas a significant positive correlation between dietary ORAC and plasma HDL was observed $(P<0.05)$.

Conclusion: Our findings suggest that dietary antioxidants is inversely associated with BMI, fasting blood glucose, triglyceride, total Cholesterol and LDL in both groups. It seems that following a diet rich in antioxidants can counteract obesity and its associated comorbidities.

\section{Background}

Obesity is a complex and multifactorial disease with a high prevalence around the world $(1,2)$. The worldwide prevalence of overweight and obesity has doubled since 1980 and about one-third of the world's population is classified as overweight or obese (2). At least 2.8 million deaths around the world are related to obesity and overweight and the prevalence of the disease is increasing annually. The disease results from complex phenotypes associated with excess fat in the body that affect other metabolic factors in addition to body size (1). Obesity is associated with numerous disorders, including diabetes, lipid profile abnormalities, liver disease, immune dysfunction and oxidative stress (3-5). It seems, body mass index (BMI) and anthropometric measurements of abdominal obesity such as the waist-hip-ratio (WHR) may serve as a risk factor for predicting metabolic syndrome and myocardial infarction (MI) (6-8).

Oxidative stress is defined by excessive endogenous oxidative species; especially reactive oxygen species (ROS), such as superoxide, hydrogen peroxide and hydroxyl radical ions which damage cells and manipulate signal pathways $(9,10)$. Fat accumulation stimulates lipid peroxidation and damage caused by free fatty acids and cytokines, such as TNF-a, leading to the exacerbation of the oxidative damage 
(11). Subjects with obesity and metabolic diseases have also shown lower levels of antioxidant activity (12); additionally, studies have shown that obesity increases the risk of metabolic syndrome in obese and overweight people due to increased oxidative stress $(5,13,14)$. On the other hand, oxidative stress disrupts insulin secretion from pancreatic beta cells (15) and induces insulin resistance (16), as well as impaired glucose transport to the muscles and the adipose tissue (15). Hyperglycemia produces alterations in various metabolic and cellular functions; including dyslipidemia, hypertension, endothelial dysfunction, and oxidative stress $(17,18)$.

In recent years, antioxidants have been used to overcome the harmful effects of ROSs. Natural antioxidants found in healthy foods, include vitamins E and C, coenzyme Q10, alpha-lipoic acid, lycopene, and polyphenols (19). The results of the studies indicate that there is an inverse relationship between body fat, central fat and antioxidant capacity (20).

Various methods are available for measuring the dietary total antioxidant capacity (TAC) $(21,22)$. According to the United States Department of Agriculture (USDA) database, the oxygen radical absorbance capacity (ORAC) index is an indicator that measures the antioxidant power of foods and other chemicals in the laboratory, and it is a preferable method because of its biological relevance to the in vivo antioxidant efficacy (23). Recent studies have shown that fruits and vegetables with high ORAC, such as spinach and blueberry, prevent chronic diseases (23-25).

Since oxidative stress, directly and indirectly, causes many diseases, including obesity and metabolic syndrome, the purpose of the present study was to investigate the relationship between the dietary ORAC index and fasting blood glucose and lipid profile in overweight/obese subjects compared to normal weight subjects.

\section{Methods}

\section{Study Type and Participants}

This study was a cross-sectional descriptive-analytic case-control study. It was carried out to show how antioxidant power of foods effects on anthropometric and biochemical parameters. The subjects were normal weight and overweight/obese adults who were randomly selected among the staff of Science and Research branch of Islamic Azad University (SRBIAU) clinic of Tehran based on their BMI using simple random method. At least 70 individuals were considered to participate in each group who has BMI $>18.5$ and age ranged between 18-65 years. All the basic required information, including BMI, anthropometric measurements and the latest blood test, were available in the University Electronic Health Clinic Database. Main inclusion criteria included $\mathrm{BMI}=18.5-24.9$ for normal group and $\mathrm{BMI}>25$ for case group also volunteers should not be under lipid and glucose control drugs, pregnant and in lactation period. Also, leaving free more than $50 \%$ of the questions in the food frequency questionnaire (FFQ) or having any inflammatory disease were exclusion criteria.

\section{Study implementation}


This study was approved by the ethical Iran National Committee for Ethics in Biomedical Research under code IR.IAU.SRB.REC.1396.66. All the eligible volunteers were informed about the details of the study and written consent were taken. On the day of referral to the SRBIAU Clinic, information about demographic characteristics was obtained through face-to-face interviews using validated questionnaires.

Anthropometric measurements, including weight and body composition, were conducted using the bioelectric impedance analyzer (INBODY, Model 270, South Korea); height was measured using a digital freestanding stadiometer (BSM-170, InBody Co. Ltd, South Korea). Dietary assessment was also carried on using a validated semi-quantitative FFQ containing 148 food items (26).

\section{Foods' ORAC measurement}

Dietary antioxidant consumption was estimated based on the ORAC index of selected foods reported by the Nutrient Data Laboratory of USDA, and expressed as $\mu \mathrm{mol}$ of Trolox Equivalents per $100 \mathrm{grams}$ of foods ( $\mu \mathrm{mol}$ TE/100 g). Based on the USDA table, we analyzed ORAC index of selected foods for each group (23).

\section{Statistical analysis method}

Independent T-test or Mann-Whitney test (in the case of nonparametric data) were used to compare the mean of quantitative outcomes between the two groups. Correlation model and multiple regression were used to find out the relationship of the variables of the study. SPSS software version 25 was used for data analysis and P-value $<0.05$ was considered as statistically significant.

\section{Results}

In the present study, the relationship between dietary ORAC index with lipid profile and fasting blood glucose in obese/overweight and normal weight population was examined. After calculating the sample size and simple random sampling, 220 adults, 110 overweight/obese and 110 with normal weight, were recruited based on the inclusion and exclusion criteria. Amongst these, 20 volunteers were excluded because of incomplete questionnaires (more than half of the items were not completed). Finally, the study was conducted with 100 normal weight and 100 overweight /obese subjects.

Basic information of two groups is presented in Table 1. As shown in Table 1, participants with normal weight had a lower visceral fat mass (five kilograms; $P<0.01)$ and a lower body fat percentage $(P<0.01)$. Waist to hip ratio (WHR) was significantly lower in the normal weight group as compared to overweight/obese group $(P<0.01)$. As expected, fasting blood glucose $(F B G)$, total cholesterol $(T C)$, triglyceride $(T G)$, and low-density lipoprotein ( $L D L)$ were higher in overweight/obese volunteers than normal volunteers, whereas HDL was greater in the normal weight group; these differences were not significant. 
Table 1

Basic information of two groups

\begin{tabular}{|llll|}
\hline Variable & Normal weight & Overweight/obese & P-Value \\
\hline N & 100 & 100 & \\
\hline Sex (M/F) & $70 / 30$ & $65 / 35$ & 0.824 \\
\hline Marital status (S/M) & $25 / 75$ & $45 / 55$ & 0.762 \\
\hline Age (year) & $40.50 \pm 8.97$ & $40.60 \pm 7.35$ & 0.915 \\
\hline Anthropometric indices, MEAN \pm SD & & & \\
\hline Weight (Kg) & $70.13 \pm 9.33$ & $95.05 \pm 12.32$ & $0.0001^{*}$ \\
\hline Height (Cm) & $172.86 \pm 4.58$ & $170.20 \pm 4.38$ & 0.856 \\
\hline BMI (Kg/m ${ }^{2}$ ) & $23.58 \pm 1.52$ & $31.28 \pm 4.16$ & $0.0001^{*}$ \\
\hline WHR & $0.88 \pm 0.04$ & $1.05 \pm 0.06$ & $0.0001^{*}$ \\
\hline Visceral fat & $7.55 \pm 2.10$ & $12.30 \pm 3.59$ & $0.0001^{*}$ \\
\hline Body fat mass (Kg) & $19.76 \pm 10.76$ & $28.77 \pm 7.48$ & $0.0001^{*}$ \\
\hline Body fat percentage (\%) & $2.14 \pm 0.78$ & $3.14 \pm 2.77$ & $0.004^{*}$ \\
\hline Biochemical parameters, MEAN \pm SD & & 0.151 \\
\hline FBG (mg/dl) & $89.01 \pm 10.73$ & $92.09 \pm 16.33$ & 0.175 \\
\hline TG (mg/dl) & $152.52 \pm 85.38$ & $164.99 \pm 84.67$ & 0.362 \\
\hline TC (mg/dl) & $172.17 \pm 35.30$ & $175.06 \pm 29.90$ & \\
\hline LDL (mg/dl) & $98.44 \pm 29.71$ & $100.22 \pm 25.75$ & \\
\hline HDL (mg/dl) & $44.51 \pm 8.41$ & $42.40 \pm 9.67$ & \\
\hline $\begin{array}{l}\text { Abbreviations: BMl, Body mass index; WHR, Waist to hip ratio; F, Female; M, Male; S, Single; M, } \\
\text { Married; }\end{array}$ & & \\
\hline FBG, Fasting blood glucose; TG, Triglyceride; TC, Total Cholesterol; LDL, low-density lipoproteins; HDL, \\
\hline high-density lipoproteins. & & & \\
\hline * P< 0.05 & & & \\
\hline
\end{tabular}

Dietary data analyses are presented in Table 2. The consumption of vegetable, fruits, vitamin C, and vitamin $\mathrm{E}$ was higher in the normal weight group than the other group; the difference was only significant in fruit consumption $(P=0.026)$. Moreover, the dietary ORAC index was higher in normal weight volunteers than the overweight/obese group; the difference, though, was not significant $(P=0.352)$. 
Table 2

Comparison of dietary intake and ORAC index in two groups of normal weight and overweight/obese

\begin{tabular}{|c|c|c|c|}
\hline Variable & $\begin{array}{l}\text { Normal weight }(n=100) \text { MEAN } \pm \\
\text { SD }\end{array}$ & $\begin{array}{l}\text { Overweight/obese }(n= \\
100) \\
\text { MEAN } \pm \text { SD }\end{array}$ & $\begin{array}{l}\mathrm{P} \text { - } \\
\text { Value }\end{array}$ \\
\hline Vegetable & $15.116 \pm 1.713$ & $12.426 \pm 1.284$ & 0.918 \\
\hline Fruits & $20.943 \pm 1.415$ & $14.246 \pm 2.702$ & $0.026^{\star}$ \\
\hline Vitamin C & $140.60 \pm 87.96$ & $123.07 \pm 74.85$ & 0.081 \\
\hline $\begin{array}{l}\text { Vitamin E (alpha- } \\
\text { tocopherol) }\end{array}$ & $11.98 \pm 10.42$ & $10.45 \pm 9.44$ & 0.064 \\
\hline ORAC & $48002.65 \pm 14651.20$ & $14785.27 \pm 8149.51$ & 0.352 \\
\hline \multicolumn{4}{|c|}{ Abbreviations: ORAC, Oxygen radical absorbance capacity. } \\
\hline$* P<0.05$ & & & \\
\hline
\end{tabular}

The correlation between the dietary ORAC index with anthropometric indices and biochemical parameters in the two groups are presented in Table 3. According to Table 3, ORAC index was inversely correlated with all anthropometric indices and biochemical parameters except for HDL. Despite significant correlation between ORAC index with BMI, WHR and HDL $(P<0.05)$, weak relationship in normal group and all subjects, and fair relation among over weight/obese group was observed. 
Table 3

Regression and Correlation coefficient between anthropometric indices and blood biochemical markers with dietary ORAC index

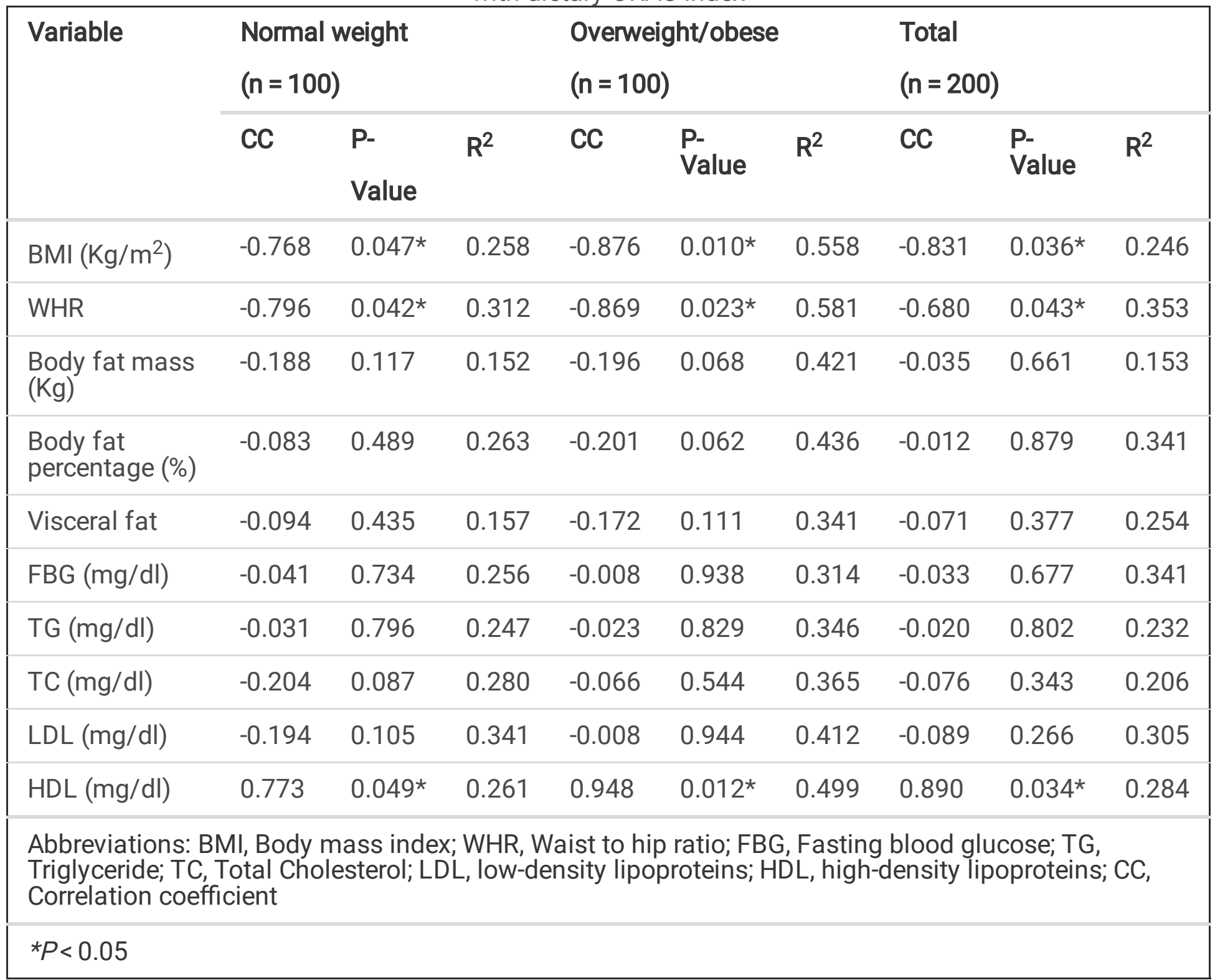

\section{Discussion}

In the present study, we were able to show that the dietary ORAC index was higher in normal weight group as compared to the overweight/obese group. In addition, there was an inverse relationship between the dietary ORAC index and anthropometric indices, FBG, TG, TC and LDL. To the best of our knowledge, this is the first study investigating the association between dietary ORAC index, body composition and plasma biochemical markers in both overweight/obese and normal weight groups. Previous studies have shown an inverse relationship between the consumption of dietary antioxidants and several outcomes such as stroke (27), hypertension (28), MI (29), cancer (30) and mortality (31).

In the present study, the dietary ORAC index was inversely correlated with BMI and WHR. In a study, Hermsdorff et al, demonstrated that dietary antioxidant capacity was negatively and significantly 
correlated with waist circumference (WC) (20). As well as, another study showed that high WHR is linked with increased oxidative stress and low concentration of antioxidant's enzyme (32). Also, among young saudi females, adipose tissue and anthropometric measurements had strong positive association with oxidative stress (33). Similarly, an increase in dietary antioxidant was shown to reduce the incidence of abdominal obesity (34). Excessive fat accumulation can lead to obesity (35), So the extra stored fat increases the production of oxygen radicals and inflammatory factors, as well as cholesterol and blood lipids (36). Excess calories inhibit the production of adiponectin (37). In the short time, the body tries to modify these damaging anomalies, but in the long run the immune system's ability to function is attenuated and oxidative stress can damage cells. Additionally, increased secretion of leptin usually accompanied by obesity leads to activation of T-lymphocytes leading to the production of proinflammatory factors, such as interleukin-2 and TNF-a which in turn can cause inflammation and oxidative stress in the body (38). The body responds to these changes by using natural antioxidants, such as vitamins $E$ and $C$. If the body is unable to eliminate these factors, excessive accumulation of oxidants can lead to impaired protein and fat function, cellular dysfunction and, ultimately, to inflammation $(5,39,40)$. Obesity-induced inflammation and oxidative stress increase insulin resistance, blood sugar, TG and metabolic syndrome $(9,41)$ by reducing the expression of insulin receptor substrate-1 (IRS-1) (42). As a result, promoting the body's antioxidant capacity can greatly prevent the complications of diabetes and metabolic syndrome $(43,44)$. Similar to the findings of the present study, many studies have shown that there was an inverse association between the dietary ORAC index with FBG, TG, LDL and TC and a positive correlation between ORAC and HDL (45-47).

Consuming antioxidant-rich foods with a high capacity to absorb oxygen radicals will give the immune system a chance to counteract inflammation(48). Despite the type of the present study as a short study, similar to the findings in the current study, the higher dietary ORAC index has been an indication of higher quality of the diet and was related to higher consumption of fruits and vegetables. The favorable effects of these antioxidant-rich foods on improvement of fasting blood glucose, lipid profile and obesity have been investigated in some pre-clinical and clinical studies(49-53). In recent years, chemical antioxidants, such as "phytochemicals", are suggested as plausible candidates in the prevention and/or treatment of specific diseases, including obesity and obesity-related metabolic disorders (54).

In line with our findings, previous studies showed that obesity is related with unhealthy diet, which is full of carbohydrate, fat, simple sugars and sweet beverages, whereas a protective effect against obesity is observed in the consumption of a diet rich in fruits and vegetables $(55,56)$ and a diet high in vegetables and fruits has been positively related to the consumption of antioxidant vitamins (56).

Some studies have also reported that antioxidant capacity in obese and overweight volunteers is promoted which was postulated to be due to immune system's trying to override the present inflammation $(57,58)$.

\section{Conclusion}


Our findings suggest that consumption of dietary antioxidant was inversely associated with $\mathrm{BMI}$ and other anthropometric measurements, FBG, TG, LDL and TC in both groups. Despite significant correlation between ORAC index with BMI, WHR and HDL, weak relationship in normal group and all subjects, and fair relation among over weight/obese group was observed. It seems that following a diet rich in ORAC can counteract obesity and its associated comorbidities.

\section{Abbreviations}

BMI, Body mass index

F, Female

FBG, Fasting blood glucose

FFQ, Food Frequency Questionnaire

HDL, high-density lipoproteins

LDL, low-density lipoproteins

M, Male

M, Married

MI, Myocardial infarction

ORAC, Oxygen radical absorbance capacity

ROS, Reactive oxygen species

S, Single

SRBIAU, Science and research branch of Islamic Azad University

TAC, Total antioxidant capacity

TC, Total Cholesterol

TG, Triglyceride

WHR, Waist to hip ratio

\section{Declarations}

\section{Ethics approval and consent to participate}


This study was approved by the ethical Iran National Committee for Ethics in Biomedical Research under code IR.IAU.SRB.REC.1396.66. All the eligible volunteers were informed about the details of the study and written consent were taken.

\section{Consent for publication}

Not applicable

\section{Availability of data and materials}

The data that support the findings of this study are available from Science and Research branch of Islamic Azad University (SRBIAU) clinic. Due to license restrictions, data of the current study is not publicly available. Data are a part of a great database and based on a contract between authors and the clinic, authors would never request for data.

\section{Competing interests}

The authors declare that they have no competing interests what so ever.

\section{Funding}

Not applicable

\section{Authors' contribution}

ZM, MM and GK wrote the manuscript. AD checked it for accuracy of English language MK and AM were adviser and supervisor of the study respectively.

\section{Acknowledgements}

Not applicable

\section{References}

1. WHO. 10 Facts on Obesity. WorldHealth Organization. World Health Organization; 2015. p. 1-3.

2. Chooi YC, Ding C, Magkos F. The epidemiology of obesity. Metabolism. 2019 Mar;92:6-10.

3. Jung UJ, Choi MS. Obesity and its metabolic complications: The role of adipokines and the relationship between obesity, inflammation, insulin resistance, dyslipidemia and nonalcoholic fatty liver disease. Vol. 15, International Journal of Molecular Sciences. MDPI AG; 2014. p. 6184-223.

4. Uranga RM, Keller JN. The complex interactions between obesity, metabolism and the brain. Vol. 13, Frontiers in Neuroscience. Frontiers Media S.A.; 2019.

5. Manna P, Jain SK. Obesity, Oxidative Stress, Adipose Tissue Dysfunction, and the Associated Health Risks: Causes and Therapeutic Strategies. Metab Syndr Relat Disord. 2015 Dec;13(10):423-44. 
6. Scicali R, Rosenbaum D, Di Pino A, Giral P, Cluzel P, Redheuil A, et al. An increased waist-to-hip ratio is a key determinant of atherosclerotic burden in overweight subjects. Acta Diabetol. 2018 Jul;55(7):741-9.

7. Twig G, Yaniv G, Levine H, Leiba A, Goldberger N, Derazne E, et al. Body-mass index in 2.3 million adolescents and cardiovascular death in adulthood. N Engl J Med. 2016 Jun;374(25):2430-40.

8. Cao Q, Yu S, Xiong W, Li Y, Li H, Li J, et al. Waist-hip ratio as a predictor of myocardial infarction risk A systematic review and meta-analysis. Vol. 97, Medicine (United States). Lippincott Williams and Wilkins; 2018.

9. Sies H. The Concept of Oxidative Stress After 30 Years. In: Biochemistry of Oxidative Stress. Springer International Publishing; 2016. p. 3-11.

10. Schieber M, Chandel NS. ROS function in redox signaling and oxidative stress. Vol. 24, Current Biology. Cell Press; 2014.

11. Marseglia L, Manti S, D’Angelo G, Nicotera A, Parisi E, Di Rosa G, et al. Oxidative stress in obesity: a critical component in human diseases. Int J Mol Sci. 2014 Dec;16(1):378-400.

12. An H, Du X, Huang X, Qi L, Jia Q, Yin G, et al. Obesity, altered oxidative stress, and clinical correlates in chronic schizophrenia patients. Transl Psychiatry. 2018 Dec;8(1).

13. Roberts CK, Sindhu KK. Oxidative stress and metabolic syndrome. Vol. 84, Life Sciences. 2009. p. 705-12.

14. Rani V, Deep G, Singh RK, Palle K, Yadav UCS. Oxidative stress and metabolic disorders: Pathogenesis and therapeutic strategies. Vol. 148, Life Sciences. Elsevier Inc.; 2016. p. 183-93.

15. Tangvarasittichai S. Oxidative stress, insulin resistance, dyslipidemia and type 2 diabetes mellitus. World J Diabetes. 2015;6(3):456.

16. Hurrle S, Hsu WH. The etiology of oxidative stress in insulin resistance. Vol. 40, Biomedical Journal. Elsevier B.V.; 2017. p. 257-62.

17. Laakso M, Kuusisto J. Insulin resistance and hyperglycaemia in cardiovascular disease development. Vol. 10, Nature Reviews Endocrinology. Nature Publishing Group; 2014. p. 293-302.

18. Bornfeldt KE, Tabas I. Insulin resistance, hyperglycemia, and atherosclerosis. Vol. 14, Cell Metabolism. 2011. p. 575-85.

19. Pizzino G, Irrera N, Cucinotta M, Pallio G, Mannino F, Arcoraci V, et al. Oxidative Stress: Harms and Benefits for Human Health. Vol. 2017, Oxidative Medicine and Cellular Longevity. Hindawi Limited; 2017.

20. Hermsdorff HHM, Puchau B, Volp ACP, Barbosa KB, Bressan J, Zulet MÁ, et al. Dietary total antioxidant capacity is inversely related to central adiposity as well as to metabolic and oxidative stress markers in healthy young adults. Nutr Metab [Internet]. 2011 Aug 22 [cited 2019 Sep 16];8(1):59. Available from: http://nutritionandmetabolism.biomedcentral.com/articles/10.1186/1743-7075-8-59 
21. Martínez-Tomé M, Murcia MA, Mariscal M, Lorenzo ML, Gómez-Murcia V, Bibiloni M, et al. Evaluation of antioxidant activity and nutritional composition of flavoured dehydrated soups packaged in different formats. Reducing the sodium content. J Food Sci Technol. 2015 Dec;52(12):7850-60.

22. Soccio M, Laus MN, Flagella Z, Pastore D. Assessment of antioxidant capacity and putative healthy effects of natural plant products using soybean lipoxygenase-based methods. An overview. Vol. 23, Molecules. MDPI AG; 2018.

23. Haytowitz D, Bhagwat S. USDA Database for the Oxygen Radical Absorbance Capacity (ORAC) of Selected Foods, Release 2. US Dep Agric. 2010;10-48.

24. Galasko DR, Peskind E, Clark CM, Quinn JF, Ringman JM, Jicha GA, et al. Antioxidants for Alzheimer disease: A randomized clinical trial with cerebrospinal fluid biomarker measures. Arch Neurol. 2012 Jul;69(7):836-41.

25. Carocho M, Ferreira ICFR, Morales P, Sokovi M. Antioxidants and prooxidants: Effects on health and aging. Vol. 2018, Oxidative Medicine and Cellular Longevity. Hindawi Limited; 2018.

26. Mirmiran P, Hosseini Esfahani F, Mehrabi Y, Hedayati M, Azizi F, Esfahani FH, et al. Reliability and relative validity of an FFQ for nutrients in the Tehran Lipid and Glucose Study. Public Health Nutr. 2010 May;13(5):654.

27. Colarusso L, Serafini M, Lagerros YT, Nyren O, La Vecchia C, Rossi M, et al. Dietary antioxidant capacity and risk for stroke in a prospective cohort study of Swedish men and women. Nutrition. 2017 Jan;33:234-9.

28. Villaverde P, Lajous M, MacDonald C-J, Fagherazzi G, Bonnet F, Boutron-Ruault M-C. High dietary total antioxidant capacity is associated with a reduced risk of hypertension in French women. Nutr J. 2019 Dec;18(1):31.

29. Rautiainen S, Levitan EB, Orsini N, Åkesson A, Morgenstern R, Mittleman MA, et al. Total antioxidant capacity from diet and risk of myocardial infarction: A prospective cohort of women. Am J Med. 2012 Oct;125(10):974-80.

30. Vece MM, Agnoli C, Grioni S, Sieri S, Pala V, Pellegrini N, et al. Dietary total antioxidant capacity and colorectal cancer in the Italian epic cohort. PLoS One. 2015 Nov;10(11).

31. Bastide N, Dartois L, Dyevre V, Dossus L, Fagherazzi G, Serafini M, et al. Dietary antioxidant capacity and all-cause and cause-specific mortality in the E3N/EPIC cohort study. Eur J Nutr. 2017 Apr;56(3):1233-43.

32. HASAn Siddiqui A, GulAti rAjiv, tAuHEEd nAZiA, PErvEZ A. Correlation of Waist-to-hip Ratio (WHR) and Oxidative Stress in Patients of Acute Myocardial Infarction (AMI) Physiology Section. J Clin Diagnostic Res. 2014;8(1):4-7.

33. Latif R, Rafique N. Association of anthropometric measurements with oxidant-antioxidant status among young Saudi females. Physiol Res. 2018;67(5):787-93.

34. Raja Kumar S, Mohd Ramli ES, Abdul Nasir NA, Ismail NHM, Mohd Fahami NA. Preventive Effect of Naringin on Metabolic Syndrome and Its Mechanism of Action: A Systematic Review. Vol. 2019, Evidence-based Complementary and Alternative Medicine. Hindawi Limited; 2019. 
35. Ellulu MS, Patimah I, Khaza'ai $H$, Rahmat A, Abed Y. Obesity and inflammation: the linking mechanism and the complications. Arch Med Sci. 2017 Jun;13(4):851-63.

36. Fernández-Sánchez A, Madrigal-Santillán E, Bautista M, Esquivel-Soto J, Morales-González A, Esquivel-Chirino C, et al. Inflammation, oxidative stress, and obesity. Int J Mol Sci. 2011;12(5):311732.

37. Nigro E, Scudiero O, Monaco ML, Palmieri A, Mazzarella G, Costagliola C, et al. New insight into adiponectin role in obesity and obesity-related diseases. Vol. 2014, BioMed Research International. Hindawi Publishing Corporation; 2014. p. 658913.

38. Procaccini C, De Rosa V, Galgani M, Carbone F, La Rocca C, Formisano L, et al. Role of adipokines signaling in the modulation of T cells function. Front Immunol. 2013 Oct;4:332.

39. Aggarwal BB. Targeting inflammation-induced obesity and metabolic diseases by curcumin and other nutraceuticals. Annu Rev Nutr. 2010 Aug;30:173-99.

40. Abdali D, Samson SE, Grover AK. How effective are antioxidant supplements in obesity and diabetes? Med Princ Pract [Internet]. 2015 [cited 2019 Sep 16];24(3):201-15. Available from: http://www.ncbi.nlm.nih.gov/pubmed/25791371

41. Farooq W, Farwa U, Khan FR. The metabolic syndrome and inflammation role of insulin resistance and increased adiposity. Oman Med J. 2015;30(2):100-3.

42. Jager J, Grémeaux T, Cormont M, Le Marchand-Brustel Y, Tanti JF. Interleukin-1 $\beta$-induced insulin resistance in adipocytes through down-regulation of insulin receptor substrate-1 expression. Endocrinology. 2007;148(1):241-51.

43. Wei J, Zeng C, Gong QY, Li XX, Lei GH, Yang TB. Associations between dietary antioxidant intake and metabolic syndrome. PLoS One. 2015 Jun;10(6).

44. Dal S, Sigrist S. The Protective Effect of Antioxidants Consumption on Diabetes and Vascular Complications. Diseases. 2016 Jul;4(4):24.

45. van der Schaft N, Schoufour JD, Nano J, Kiefte-de Jong JC, Muka T, Sijbrands EJG, et al. Dietary antioxidant capacity and risk of type 2 diabetes mellitus, prediabetes and insulin resistance: the Rotterdam Study. Eur J Epidemiol [Internet]. 2019 Sep 9 [cited 2019 Sep 27];34(9):853-61. Available from: http://link.springer.com/10.1007/s10654-019-00548-9

46. Kim K, Vance TM, Chun OK. Greater Total Antioxidant Capacity from Diet and Supplements Is Associated with a Less Atherogenic Blood Profile in U.S. Adults. Nutrients. 2016 Jan;8(1).

47. Casas-Grajales S. Antioxidants in liver health. World J Gastrointest Pharmacol Ther. 2015;6(3):59.

48. Hussain T, Tan B, Yin Y, Blachier F, Tossou MCB, Rahu N. Oxidative Stress and Inflammation: What Polyphenols Can Do for Us? Oxid Med Cell Longev. 2016;2016.

49. Solverson PM, Henderson TR, Debelo H, Ferruzzi MG, Baer DJ, Novotny JA. An Anthocyanin-Rich Mixed-Berry Intervention May Overweight and Obese Adults. 2019;

50. Fraga CG, Croft KD, Kennedy DO, Tomás-Barberán FA. The effects of polyphenols and other bioactives on human health. Food Funct. 2019;10(2):514-28. 
51. Papada E, Kaliora AC. Antioxidant and anti-inflammatory properties of mastiha: A review of preclinical and clinical studies. Antioxidants. 2019;8(7).

52. Bahadoran Z, Golzarand M, Mirmiran P, Shiva N, Azizi F. Dietary total antioxidant capacity and the occurrence of metabolic syndrome and its components after a 3-year follow-up in adults: Tehran Lipid and Glucose Study. Nutr Metab. 2012;9:1-9.

53. Azzini E, Giacometti J, Russo GL. Antiobesity Effects of Anthocyanins in Preclinical and Clinical Studies. Oxid Med Cell Longev. 2017;2017(ii).

54. Mopuri R, Islam MS. Medicinal plants and phytochemicals with anti-obesogenic potentials: A review. Vol. 89, Biomedicine and Pharmacotherapy. Elsevier Masson SAS; 2017. p. 1442-52.

55. Yannakoulia M, Ntalla I, Papoutsakis C, Farmaki AE, Dedoussis G V. Consumption of vegetables, cooked meals, and eating dinner is negatively associated with overweight status in children. $J$ Pediatr. 2010 Nov;157(5):815-20.

56. Karfopoulou E, Brikou D, Mamalaki E, Bersimis F, Anastasiou CA, Hill JO, et al. Dietary patterns in weight loss maintenance: results from the MedWeight study. Eur J Nutr. 2017 Apr;56(3):991-1002.

57. Savu O, Ionescu-Tirgoviste C, Atanasiu V, Gaman L, Papacocea R, Stoian I. Increase in Total Antioxidant Capacity of Plasma despite High Levels of Oxidative Stress in Uncomplicated Type 2 Diabetes Mellitus. J Int Med Res. 2012 Apr;40(2):709-16.

58. Petelin A, Tedeschi P, Maietti A, Jurdana M, Brandolini V, Pražnikar ZJ. Total Serum Antioxidant Capacity in Healthy Normal Weight and Asymptomatic Overweight Adults. Exp Clin Endocrinol Diabetes. 2017 Jul;125(7):470-7. 